\title{
MATHEMATICAL MODELING OF AGGLOMERATES EVOLUTION
}

\author{
V. A. Babuk, N. L. Budnyi, and A. A. Nizyaev \\ Baltic State Technical University "VOENMEH" \\ 1 First Krasnoarmeyskaya Str., St. Petersburg 190005, Russia
}

The model of evolution of the condensed products as a part of a flow of combustion products of solid propellant is developed. The model includes the description of physical and chemical transformations for two basic fractions of the condensed products: agglomerates and smoke oxide particles (SOPs). Model testing is carried out using experimental data about evolution of the condensed products for two compositions in the conditions of a one-dimensional flow. These compositions differ considerably in properties of combustion products at a surface of burning propellant. The results of testing give the grounds to draw a conclusion about high enough quality of modeling.

\section{INTRODUCTION}

The properties of the condensed combustion products (CCP) play a significant role at engine functioning. These properties are a consequence of realization of two processes: process of propellant burning and process of evolution of the condensed products as a part of a flow of combustion products of propellant. The first process defines characteristics of the condensed products at the surface of burning propellant and the second - the specified characteristics during set of physical and chemical transformations which take place during movement of particles of the condensed phase.

The condensed products consist of two fractions: agglomerates (coarse fraction of CCP) and SOPs (fine fraction of CCP). While the properties of coarse fraction basically define character of processes in the combustion chamber (slagformation, interaction of combustion products with motor elements), properties of fine fraction basically influence the losses of a specific impulse and stability of motor work. Main attention has been drawn on studying of process of agglomerates evolution earlier. In the present work, attention is mainly accented on studying of SOP evolution as a part of a flow of combustion products.

(C) The Authors, published by EDP Sciences. This is an open access article distributed under the terms of the Creative Commons Attribution License 4.0 (http://creativecommons.org/licenses/by/4.0/). 


\section{EXPERIMENTAL RESEARCH OF EVOLUTION PROCESS OF THE CONDENSED PRODUCTS IN A GAS PHASE}

The carried out work is based on the results of an experimental research of evolution of the condensed products depending on time of stay in a gas phase. The technique of this research is described in [1]. Specimens of propellant are burnt in a constant volume bomb in the environment of inert gas using special protective tubes (Fig. 1). The length of these tubes $\left(L_{s}\right)$ defines time of stay of the condensed products in the environment of products of combustion not revolted with external factors.

Collection of all condensed products is carried out at the exit of tube. Further, the all-round analysis of these products is carried out. The mass fraction of collected products makes value not less than $95 \%$. The results of the analysis allow to obtain the following quantitative information:

$f_{m}(D)$ - mass function of agglomerate size distribution density;

$f_{m}(d)$ - mass function of SOP size distribution density;

$D_{43}$ - mass average diameter of agglomerates;

$d_{43}$ - mass average diameter of SOPs;

$Z_{m}$ - fraction of unburned metal in the agglomerates relative to the original aluminum in the propellant;

$Z_{m}^{\text {ox }}$ - fraction of original metal in the propellant used to form oxide in the agglomerates;

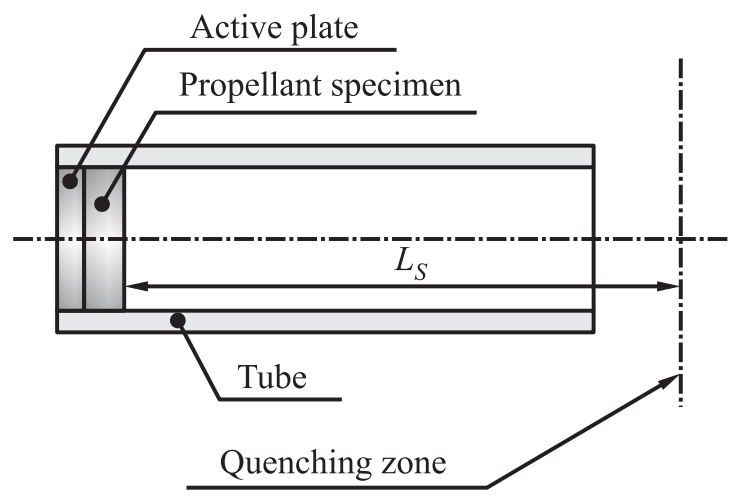

Figure 1 The scheme of carried out experiment 
$Z_{m}^{a}$ - fraction of original metal in the propellant used to form the agglomerates as a whole;

$Z_{m}^{\mathrm{SOP}}$ - fraction of original metal in the propellant used to form SOP;

$\eta$ - mass fraction of oxide in agglomerates.

Let us notice definition problems of $f_{m}(d)$ connected with high propensity to coagulation of collected SOP that can lead to distortion of the measured size of the particles. These problems are aggravated at use of the protective tubes made of plexiglass and polytetrafluoroethylene. Ways of the solution of the specified problems are considered in $[2,3]$.

The results of visualization of agglomerates in a gas phase are used for obtaining the information of qualitative character [1].

The obtained experimental results have allowed formulating the general physical picture of $\mathrm{CCP}$ evolution in a gas phase. It is possible to define it as follows (Fig. 2).

Agglomerates are the basic source of evolution process. They provide realization of physical and chemical transformations which define the properties of both coarse and fine fractions of CCP. Let us note the basic phenomena which are taking place during evolution:

- burning of agglomerate metal in gas-phase mode;

- SOP formation in a zone of burning of agglomerates metal and their coagulation;

- chemical interaction of the condensed metal and oxide of agglomerate with formation of gaseous products;

- deposition of SOP from external gas flow on agglomerate and their interaction with "substance" of agglomerate;

- change of structure of agglomerate;

- delivery of SOP from a zone of agglomerates burning to carrier gas phase; and

- motion of agglomerate and SOPs.

Completion of evolution process in the motor chamber is connected with formation of two basic fractions of CCP: coarse and fine. 


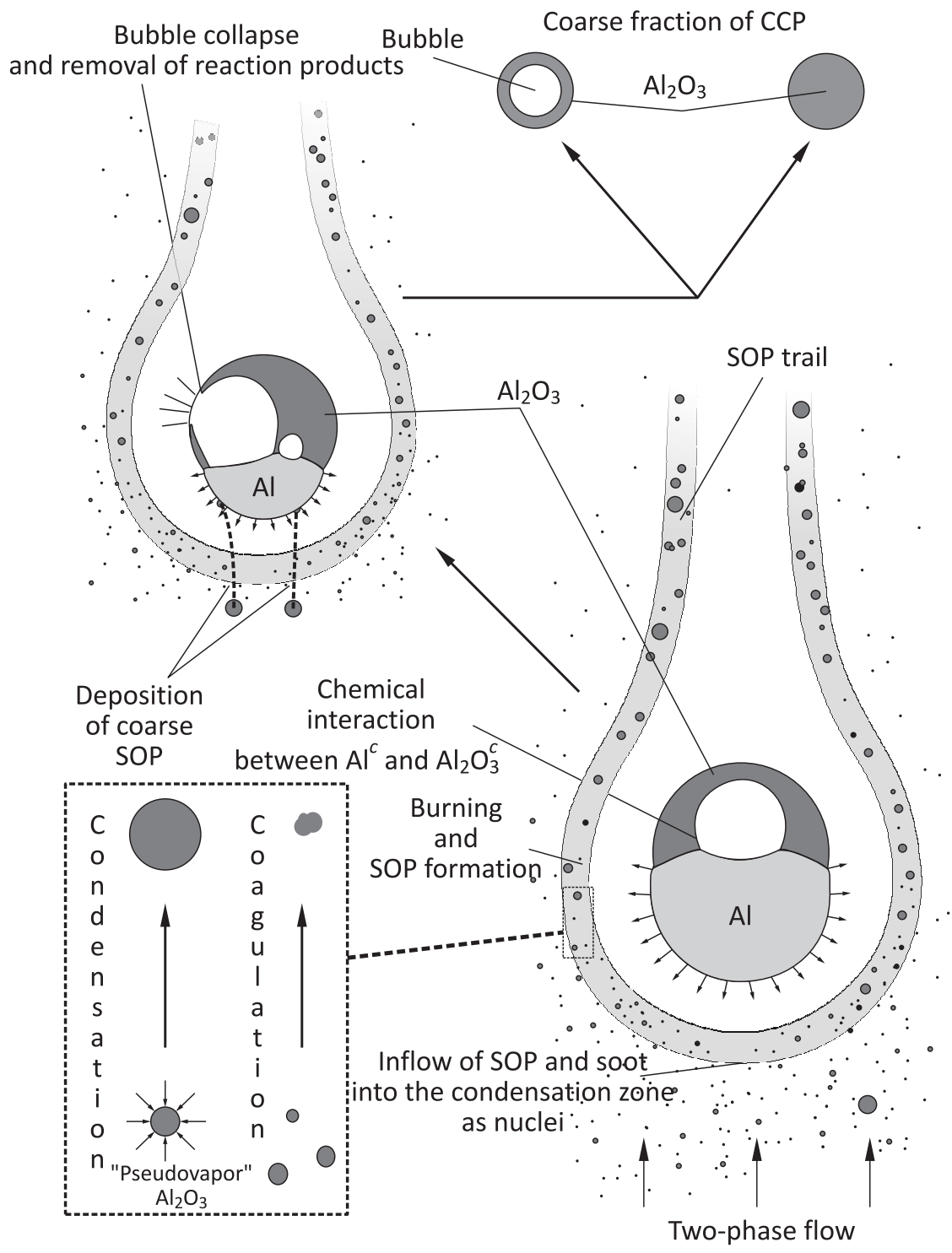

Figure 2 A diagram illustrating the evolution of condensed products 


\section{MATHEMATICAL MODEL OF EVOLUTION PROCESS}

Considering the formulated physical picture of evolution process, it is expedient that the mathematical model of this process should be based on mathematical models of evolution of agglomerate and SOP.

\subsection{Agglomerate Evolution}

The mathematical model of evolution of agglomerates has been developed earlier [4]. This model represents the set of particular models of the separate phenomena cooperating among themselves (Fig. 3):

(1) metal burning;

(2) interaction $\mathrm{Al}^{c}+\mathrm{Al}_{2} \mathrm{O}_{3}^{c}$;

(3) deposition of SOP on agglomerate;

(4) structure; and

(5) agglomerate motion.

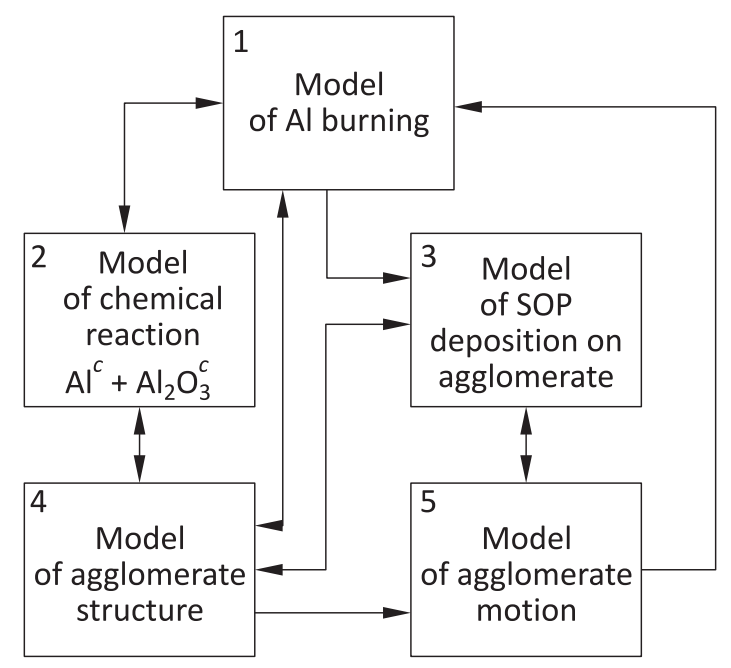

Figure 3 Block-diagram of the model of single agglomerate evolution [4] 
The comparison of the results of the numerical analysis of the model with experimental data led to conclusion about sufficiently high quality of modeling [4]. In the present edition, the model is subjected modernization which included:

- the account of presence of various kinds of structure of agglomerates besides agglomerate with "cap oxide" ("matrix" agglomerate, "hollow" agglomerate); and

- the description of burning under condition of presence in the environment of combustion products a significant amount of molecular oxygen $\left(\mathrm{O}_{2}\right)$.

\subsection{Formation and Evolution of Smoke Oxide Particles}

Let us notice that the quantity of the works devoted to oxide particles formation during burning of aluminum drops is extremely limited.

Kinetics of chemical reactions with participation of aluminum suboxides leading to condensed oxide formation is considered in [5]:

$$
\begin{gathered}
\mathrm{Al}_{2} \mathrm{O}+2 \mathrm{CO}_{2}=\mathrm{Al}_{2} \mathrm{O}_{3}^{c}+2 \mathrm{CO} \\
2 \mathrm{AlO}+\mathrm{CO}_{2}=\mathrm{Al}_{2} \mathrm{O}_{3}^{c}+\mathrm{CO} \\
\mathrm{Al}_{2} \mathrm{O}+2 \mathrm{H}_{2} \mathrm{O}=\mathrm{Al}_{2} \mathrm{O}_{3}^{c}+2 \mathrm{H}_{2} \\
2 \mathrm{AlO}+\mathrm{H}_{2} \mathrm{O}=\mathrm{Al}_{2} \mathrm{O}_{3}^{c}+\mathrm{H}_{2}
\end{gathered}
$$

However, the question about the mechanism of condensation and size of oxide particles remains opened.

Within the limits of model of work [6], homogeneous condensation is considered and kinetics is described. However, the data on size of particles of the formed oxide are absent.

In [7], the model related to fine metal particle surrounded by active motionless environment is suggested, according to which characteristic time of diffusion of oxidizing gases is much less than the characteristic time of heterogeneous chemical reaction on formed nuclei of the condensed phase. The model is based on the positions of work [8] about burning of metal drops. It provides definition of function of oxide particle size distribution. Absence of comparison of numerical and experimental data does not allow to estimate the quality of modeling. Besides, as it was specified in [4], many positions of work [8] contradict with the available experimental data.

There are a number of works devoted to simulation of multiphase flow in combustion chamber of solid rocket motor (see, for example, [9-13]). However, it has to be stated that some questions are unconsidered in these works. First of 
all, there are the questions related to various processes and phenomena during agglomerates evolution and also, the SOP size distribution transformation during evolution of CCP flow.

Let us consider the model developed in the present work. It is based on a number of assumptions. Their introduction is based on the following considerations.

The results of experimental researches of evolution process of an agglomerates flow $[1,4]$ have allowed to draw an important conclusion: agglomerate metal burns in diffusion mode in the environment of combustion products of propellant. This circumstance allows to consider the variety of burning processes as "fast" processes. It is necessary to underline that this statement is not universal in relation to burning of aluminum drops in any active environments. The results of experimental study of agglomerates evolution processes in the environment of cold air indicate the influence of the kinetic factors.

Environment in which the burning process takes place is "dirty" environment, figuratively speaking: the gas phase is saturated by liquid aluminum oxide particles and solid carbon particles (soot). Such properties of environment do rather probable heterogeneous character of condensation process.

Formation of various boundary layers (dynamic, thermal, diffusion, etc.) takes place during interaction of a gas flow with agglomerate. Characteristics of one of these layers allow to estimate spatial position of others.

The flow in vicinity of agglomerate and, as a consequence, formation of "trail" (Fig. 4) is accompanied by realization of elements of jet flows which are characterized by laminar-turbulent transition at rather low Reynolds numbers [14, 15]. However, the comparison of numerical results in laminar formulation (cal-

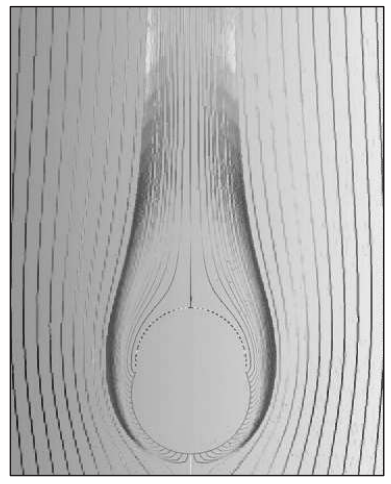

(a)

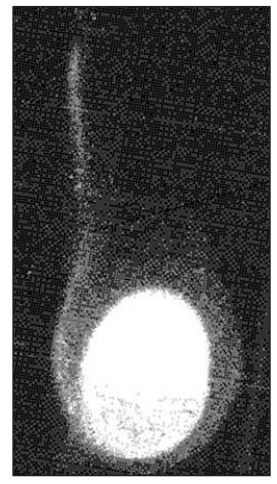

(b)

Figure 4 Gas flow in vicinity of agglomerate: $(a)$ numerical result - streamlines of gas velocity field; and $(b)$ experimental visualization 
culations were carried out for chemically homogeneous flow) with experimental visualization picture gives a ground to make a conclusion about their proximity (see Fig. 4).

Considering described above, the following positions have been used in modeling:

- condensation takes place in a heterogeneous mode;

- nuclei of a new phase are SOPs and soot of environment;

- condensation is the "fast" process;

- coagulation is defined by the Brownian motion;

- the flux of substances to the "trail" is defined by diffusion model of metal burning;

- spatial position of a zone of condensation is defined by parameters of a dynamic boundary layer; and

- the thickness of condensation zone $\left(\delta_{c}\right)$ is equal to the width of a zone of the equilibrium condensation and is calculated using the model of vapor-phase metal burning.

The modified continuous approach for the description of transformation of size distribution is used. According to this approach, change of parameters of functions of distribution in the sizes for a discrete time interval leads to necessity of redistribution of particles between fractions for the description of evolution of particles for the following time interval. The expediency of updating of the standard continuous approach [16] is caused by a significant growth of SOP due to condensation.

In general, change of quantity of the particles belonging to the $i$ th fraction along curvilinear coordinate is expressed by the following ordinary differential equations:

$$
\frac{d n_{i}}{d x_{k}}=\frac{1}{u_{x_{k}}^{\mathrm{av}}\left(x_{k}\right)}\left(-n_{i} \sum_{j=i}^{N} K_{i j} n_{j}+\dot{n}_{i}+w_{i}-\dot{n}_{i}^{g}\right)
$$

where $N$ is the quantity of fractions; $i$ and $j$ are the indexes of corresponding fractions; $n_{i}$ is the number of particles of the $i$ th fraction in volume unit; $x_{k}$ is the curvilinear coordinate connected with a streamline along which the condensation zone is located; $K_{i j}$ is the factor of Brownian coagulation between particles of the $i$ th and $j$ th fractions; $\dot{n}_{i}$ is the change of number of particles of the $i$ th fraction in volume unit due to inflow of new nuclei from environment per unit of time; $w_{i}$ is the change of number of particles of the $i$ th fraction in unit of volume per unit of time due to "redistribution" - transition of the 
enlarged particles in the $i$ th fraction from finer fractions and transition of the enlarged particles from the $i$ th fraction to coarser fractions; $\dot{n}_{i}^{g}$ is the change of number of particles of the $i$ th fraction in volume unit per unit of time due to change of geometrical sizes of condensation zone; and $u_{x_{k}}^{\text {av }}\left(x_{k}\right)$ is the average component of speed in a projection on $x_{k}$ in any section of a condensation zone.

Determination of $w_{i}$ is based on calculation of change in mass of particles of different fractions which is described by the following equations:

$$
\frac{d m_{i}}{d x_{k}}=\frac{1}{u_{x_{k}}^{\mathrm{av}}\left(x_{k}\right)}\left(\sum_{j=i}^{i-1} K_{i j} n_{j} m_{j}+\Omega_{i} I_{\Omega}\right)
$$

where $\Omega_{i}$ is the surface area of the $i$ th fraction of SOP; $m_{i}$ is the mass of the particle of the $i$ th fraction; and $I_{\Omega}$ is the mass of oxide "pseudovapor" attached to unit of surface area of the particles per unit of time.

Determination of the size distribution function of formed SOP produced by integrating system of ordinary differential equations (1) along curvilinear coordinate (associated with streamline) with the implementation of the algorithm of particles "redistribution" between the factions, which is determined by solving the system of Eqs. (2). Integration is performed until coordinate value $x_{k}^{\text {end }}$, wherein $u_{x^{k}}^{\text {av }}\left(x_{k}\right)$ differs from carrier gas velocity by a predetermined small value, is not reached.

Schematically, the spatial position of the condensation zone is shown in Fig. 5.
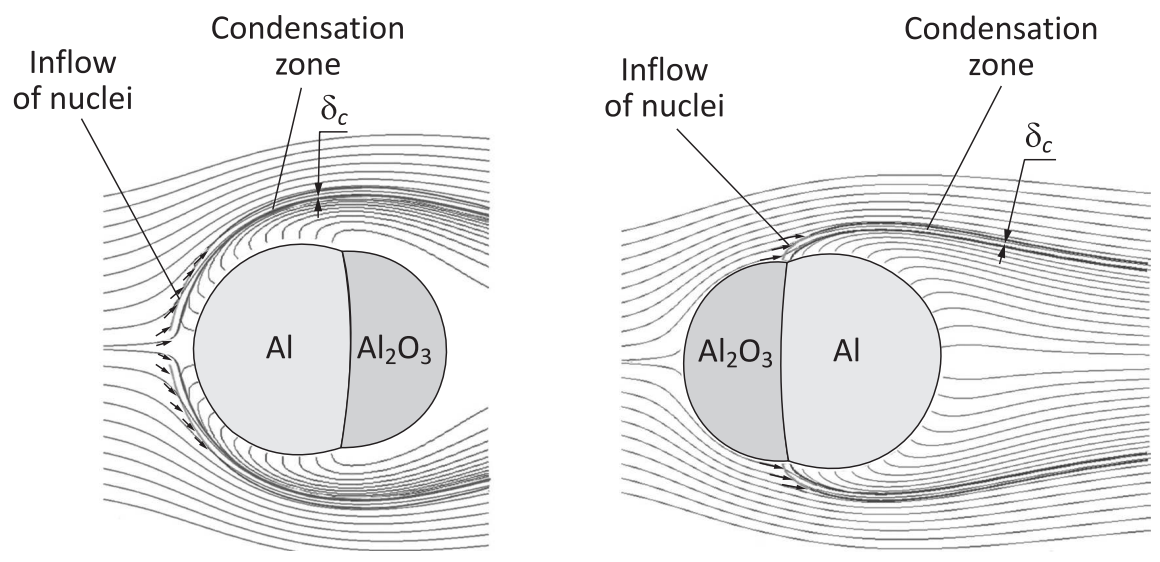

Figure 5 The scheme of a spatial position of condensation zone (streamlines of gas velocity field are shown) 


\section{TESTING THE MODEL}

Two propellants compositions [2] were used to test the model. The propellants contained $24 \%$ of aluminum, $64 \%$ of ammonium perchlorate, $11.6 \%$ of isoprene rubber with plasticizer, and $0.4 \%$ of other additives. Propellant compositions significantly differed in particle size of oxidizer $(1-50 \mu \mathrm{m}$ for N1 and $400-600 \mu \mathrm{m} \mathrm{N5}$ ). Calculation of the evolution process of the totality of the condensed products (agglomerates and SOPs) studied formulations was carried out.

Changing the oxidation potential of the medium $\left(a_{k}\right)$ and temperature $\left(T_{f}\right)$, as a result of the combustion of metal agglomerates, was taken into account during the calculation. Dependencies $a_{k}\left(Z_{m}\right)$ and $T_{f}\left(Z_{m}\right)$ were determined using thermodynamic method [2]. It was assumed that the totality of SOPs that leave the surface of burning propellant is involved in evolution process. This statement is due to the fact that in the process of burning, propellant surface portions, which supply agglomerates and SOPs, constantly alternate.

It can be noted that the model of evolution agglomerates describes quite well the characteristics of the agglomerates (Figs. 6 and 7). This circumstance was also underlined in [4].
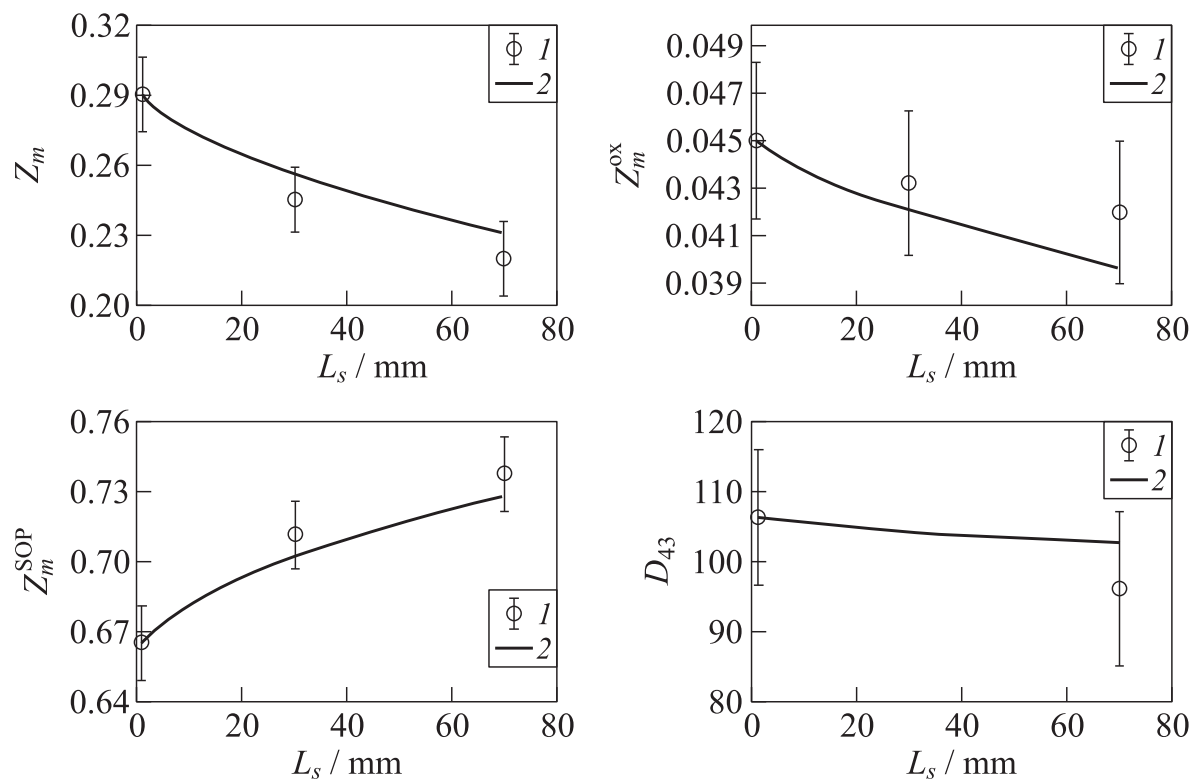

Figure 6 Parameters of agglomerates evolution for composition N1 $(P=1.0 \mathrm{MPa})$ : 1 - experimental; and 2 - numerical 

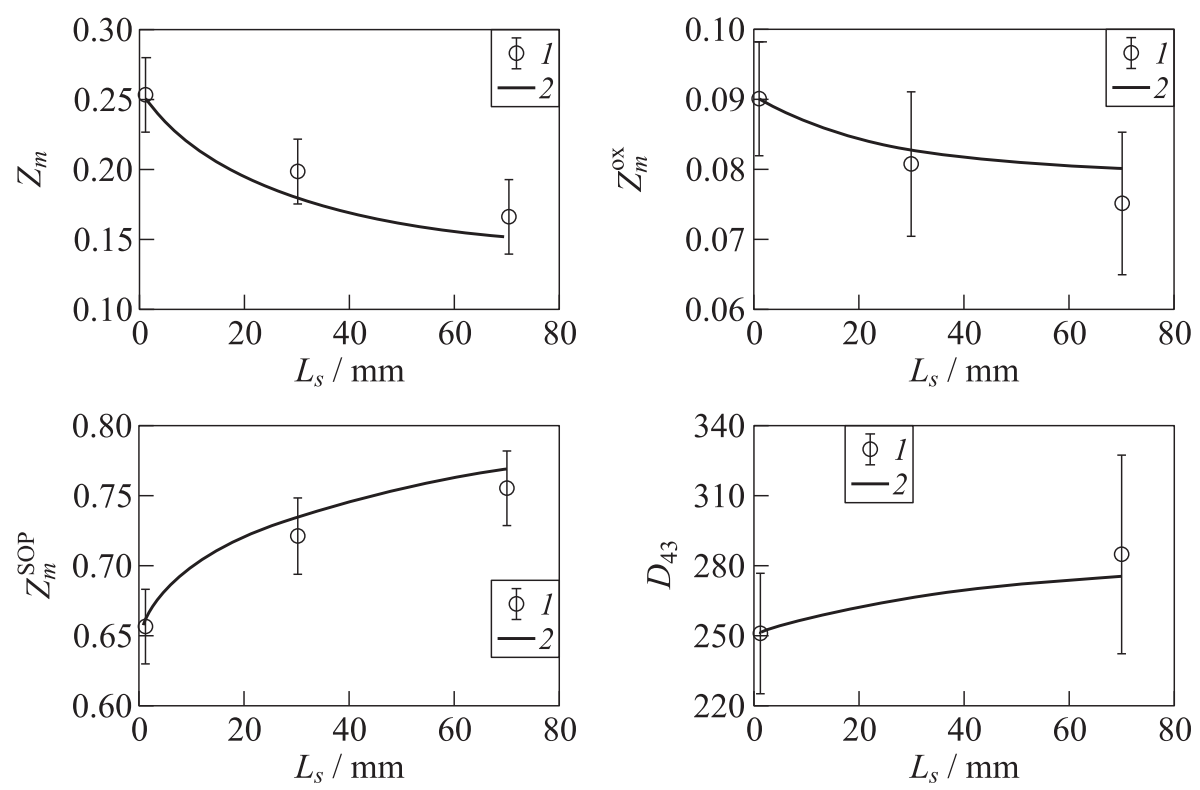

Figure 7 Parameters of agglomerates evolution for composition N5 $(P=6.0 \mathrm{MPa})$ : 1 - experimental; and 2 - numerical

The structure of agglomerates $\left(D=D_{43}\right)$ for formulations was investigated after the evolution process and is shown in Fig. 8.

Let us consider process of SOP evolution in details. As a rule, the increase in the size of particles during evolution occurs [1]. This circumstance is an objective reality and is not connected with increase of coagulation intensity of the collected particles using protective tubes. Photograph of the selected particles

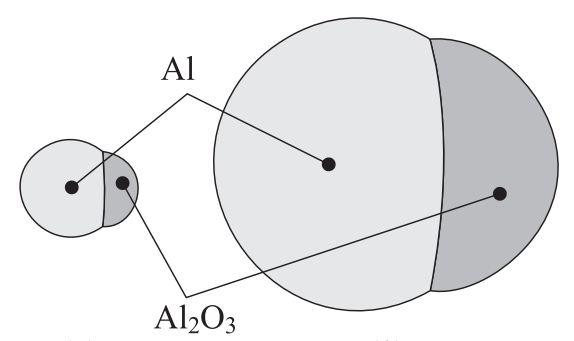

(a)

(b)

Figure 8 Structure of agglomerates: (a) N1, pressure $1 \mathrm{MPa}$; and (b) N5, pressure $6 \mathrm{MPa}$ 


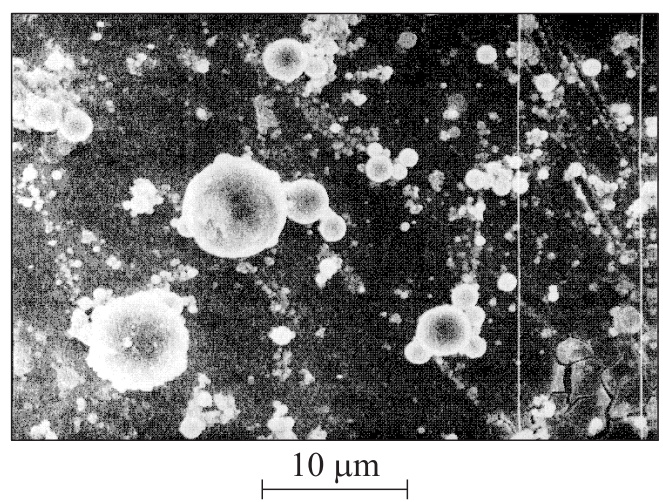

Figure 9 Collected SOP

for composition N5 $\left(L_{s}=70 \mathrm{~mm}\right)$ is resulted in Fig. 9. Large SOPs have the correct spherical form that gives the grounds to speak about a reality of presence of such particles in a flow of combustion products.

As a whole, the traditional situation for composition N5 is experimentally observed: the size of SOPs increases during evolution.

Two situations are experimentally observed for composition N1 at low and high pressure. The size of SOPs increases during evolution at low pressure, and at a high pressure, it remains almost invariable.

Calculation of SOP size distribution after the end of evolution process was carried out in the following sequence. At first, shares of SOP, which get to the condensation zone from flow around agglomerate, were determined for different fractions of agglomerates. Then, degree of enlargement of these particles in a condensation zone was found using the developed model, i. e., the function of SOP size distribution on an exit from a condensation zone was defined. Further, total function $f_{m}(d)$ was defined taking into account mass shares of various fractions of SOPs.

In general, one can speak about a satisfactory agreement between the calculated and experimentally determined parameters of the distribution laws of SOP size (Figs. 10 and 11). Use of the model of SOP evolution allows to understand the nature of fixed experimental laws of change of SOP size.

Essential enlargement of SOPs for composition N5 (see Fig. 11) is caused, mainly, by considerable times of stay of these particles in a condensation zone. Composition N1 differs essentially in higher burning rate $\left(r_{b}=34.0 \mathrm{~mm} / \mathrm{s}\right.$ at $P=1.0 \mathrm{MPa}$ and $r_{b}=58.4 \mathrm{~mm} / \mathrm{s}$ at $P=6.0 \mathrm{MPa}$ ) in comparison with composition N5 $\left(r_{b}=5.9 \mathrm{~mm} / \mathrm{s}\right.$ at $P=1.0 \mathrm{MPa}$ and $r_{b}=8.1 \mathrm{~mm} / \mathrm{s}$ at $\left.P=6.0 \mathrm{MPa}\right)$. This circumstance leads to sharp increase of speed of a carrier gas flow for composition N1, a consequence of that is decrease of time of SOP stay in a condensation 


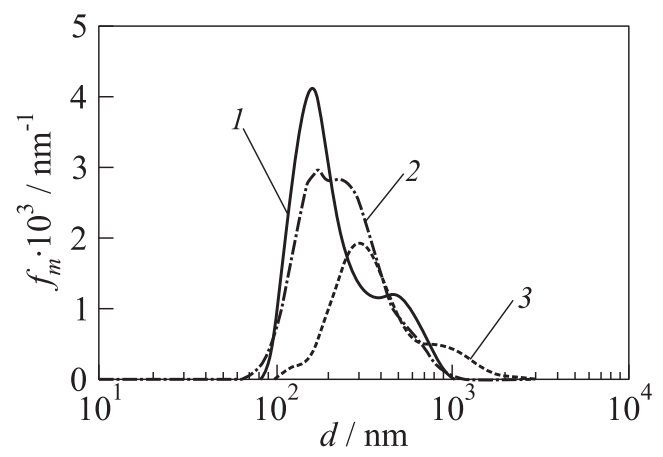

(a)

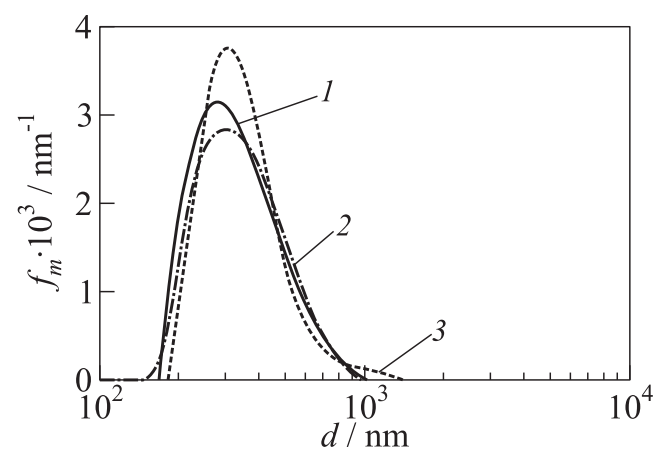

(b)

Figure 10 Mass functions of SOP size distribution density for N1 composition: (a) pressure $1 \mathrm{MPa}$; and (b) pressure $6 \mathrm{MPa} ; 1-L_{s}=1 \mathrm{~mm} ; 2-L_{s}=70 \mathrm{~mm}$, numerical; and $3-L_{s}=70 \mathrm{~mm}$, experimental

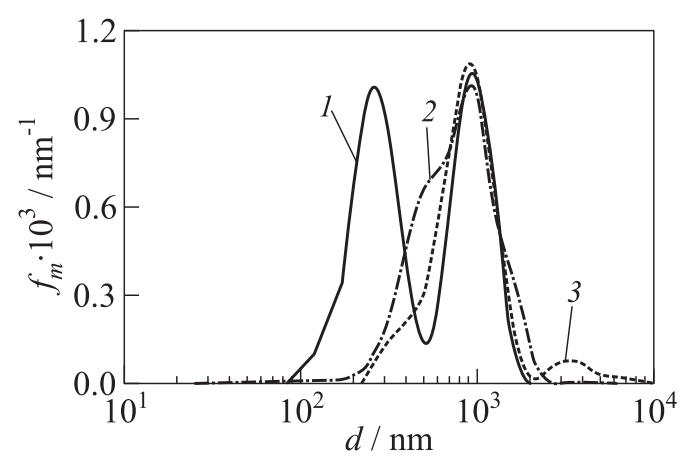

Figure 11 Mass function of SOP size distribution density for N5 composition, pressure $6 \mathrm{MPa}: 1-L_{s}=1 \mathrm{~mm} ; 2-L_{s}=70 \mathrm{~mm}$, numerical; and $3-L_{s}=70 \mathrm{~mm}$, experimental 
Table 1 Calculated and experimental values of $d_{43}$

\begin{tabular}{ccccc}
\hline \multirow{2}{*}{ Composition } & Pressure, & \multicolumn{2}{c}{$d_{43}, \mu \mathrm{m}$} & \multirow{2}{*}{ EPror } \\
\cline { 3 - 4 } & $\mathrm{MPa}$ & Experimental & Calculated & \\
\hline N1 & 1 & $0.53 \pm 0.12$ & 0.34 & $18.1 \%$ \\
N1 & 6 & $0.42 \pm 0.09$ & 0.43 & - \\
N5 & 6 & $1.35 \pm 0.30$ & 1.04 & $0.9 \%$ \\
\hline
\end{tabular}

zone. At a high pressure, enlargement of these particles is practically absent (see Fig. 10b).

The original situation takes place at low pressure. Substantial growth of speed of a carrier gas flow occurs owing to pressure drop. It leads to increase in intensity of deposition of SOPs at agglomerates. The coefficient of SOP deposition on the agglomerate, which represents the fraction of SOPs deposited on the agglomerate in relation to SOPs moving in the flow within tube with diameter equal to diameter of the agglomerate, increases essentially.

It is obvious that, first of all, large particles are deposited. Thus, original separation of SOP occurs and only rather small particles get into the condensation zone, which enlargement is rather considerable. The specified phenomena: deposition of the largest SOPs on agglomerates and essential enlargement of SOPs in condensation zone also lead finally to increase in the sizes of SOPs after end of evolution process (see Fig. 10a).

The results of the carried out analysis give the grounds to ascertain that use of the developed model allows to obtain the data on size distribution of SOPs which, as a rule, are in limits of confidential intervals that have been found experimentally (Table 1). The error has higher value for composition N1 at low pressure. It reaches the values of $\sim 20 \%$. Thus, there is a problem of carrying out of more detailed researches with reference to a specific situation which takes place in the specified conditions. However, as a whole, it is possible to speak about high enough quality of modeling of SOP evolution process. The results of modeling allow obtaining realistic function of SOP size distribution in the course of evolution.

\section{CONCLUDING REMARKS}

The basic result of the present work is the development of mathematical model of evolution of the condensed products as a part of a flow of combustion products. The model provides the description of physical and chemical transformations of two basic fractions: agglomerates and SOPs. Testing of model for compositions, which essentially differ in properties of combustion products at a surface 
of burning propellant, is carried out for conditions of a one-dimensional flow. The results of testing give the grounds to speak about high enough quality of modeling.

\section{REFERENCES}

1. Babuk, V.A., V.A. Vasilyev, and P. A. Naslednikov. 2001. Experimental study of evolution of condensed combustion products in gas phase of burning solid rocket propellant. Combustion of energetic materials. Eds. K. Kuo and L. De Luca. New York, NY. 412-426.

2. Babuk, V.A., V.A. Vasilyev, and M.S. Malakhov. 1999. Condensed combustion products at the burning surface of aluminized solid propellant. J. Propul. Power 15:783-793.

3. Babuk, V.A. 2007. Problems in studying formation of smoke oxide particles in combustion of aluminized solid propellants. Combust. Explo. Shock Waves 43:3845 .

4. Babuk, V. A., and V. A. Vasilyev. 2002. Model of aluminum agglomerate evolution in combustion products of solid rocket propellant. J. Propul. Power 18:814-824.

5. Orlandi, O., S. Gallier, Y. Moonsamy, and N. Ceso. 2013. Numerical simulation of a single aluminum droplet burning in a propellant environment. 5th European Conference for Aerospace Sciences Proceedings. Munich, Germany.

6. Liang, Y., M. W. Beckstead, and K. Pudduppakkam. 1999. Numerical simulation of unsteady single aluminum particle combustion. 36th JANNAF Combustion Meeting. CPIA No. 691. 1:283-309.

7. Gremyachkin, V. M., A. G. Istratov, and O. I. Leipunskii. 1974. Formation of condensed oxide particles by combustion of metal droplets. J. Appl. Mech. Tech. Phys. 15:494-499.

8. Gremyachkin, V.M., A. G. Istratov, and O. I. Leipunskii. 1975. Model for the combustion of metal droplets. Combust. Explo. Shock Waves 11:313-318.

9. Salita, M. 1995. Deficiencies and requirements in modeling of slag generation in solid rocket motors. J. Propul. Power 1:10-23.

10. Dupays, J., Y. Fabignon, P. Villedieu, G. Lavergne, and J. L. Estivalezes. 2000. Some aspects of two-phase flows in solid-propellant rocket motors. Solid propellant chemistry, combustion and motor interior ballistics. Eds. V. Yang, T. B. Brill, and W. Z. Ren. Progress in astronautics and aeronautics ser. Reston: AIAA. 185: 859883.

11. Jackson, T. L., F. Najjar, and J. Buckmaster. 2005. New aluminum agglomeration models and their use in solid-propellant-rocket simulations. J. Propul. Power 5:925936.

12. Attili, A., B. Favini, M. Di Giacinto, and F. Seraglia. 2009. Numerical simulation of multiphase flows in solid rocket motors. 45th AIAA/ASME/SAE/ASEE Joint Propulsion Conference \& Exhibit. Denver, CO. 
13. Maggi, F., S. Dossi, and L. T. DeLuca. 2013. Combustion of metal agglomerates in a solid rocket core flow. Acta Astronaut. 2:163-174.

14. Abramovich, G. N., S. Yu. Krasheninnikov, A. N. Sekundov, and I. P. Smirnova. 1974. Turbulentnoe smeshenie gazovykh struy [Turbulent mixing of gas jets]. Moscow: Nauka. 272 p.

15. Abramovich, G. N., T. A. Girshovich, S. Yu. Krasheninnikov, A. N. Sekundov, and I. P. Smirnova. 1984. Teoriya turbulentnukh struy [The theory of turbulent jets]. Moscow: Nauka. 716 p.

16. Sternin, L.E., and A. A. Shraiber. 1994. Mnogofaznye techeniya gaza s chastitsami [Multiphase flows of gas with particles]. Moscow: Mashinostroenie. 320 p. 